\title{
I989-2009: VEINTE AÑOS DE «DESENCUENTROS» ENTRE LA LEY PENAL Y LA REALIDAD DE LA VIOLENCIA EN LA PAREJA
}

\author{
María Luisa MAQUEDA ABREU \\ CATEDRÁTICA DE DERECHO PENAL \\ UNIVERSIDAD DE GRANADA
}

\section{Primer Periodo (1989-2003)}

Fue en 1989 cuando el problema de la violencia en la pareja adquirió una dimensión pública en el Estado español. Un Informe de la Comisión de Derechos Humanos del Senado, publicado ese mismo año, sirvió de impulso al reconocimiento de su relevancia social y de la necesidad de separarlo del contexto íntimo y privado de las relaciones familiares bajo el que se encontraba oculto ${ }^{\mathrm{I}}$. La influencia del movimiento feminista se hizo evidente en esta primera fase de reivindicación de la realidad del maltrato contra la mujer y de su consideración como un hecho estructural, producto de razones históricas y culturales que condicionan su existencia. Entre ellas, citaba el Informe, la dependencia económica, el reparto de papeles y funciones dentro de la familia en la que la mujer sigue teniendo la consideración de subordinada o el mantenimiento de los estereotipos sexuales... ${ }^{2}$. Quedaba claro que el discurso que se estaba utilizando para denunciar públicamente el maltrato en la pareja era ya el de la violencia de género.

Pero el legislador penal no se percató de ello, de modo que, cuando decidió tipificar como delito ese maltrato, lo hizo siguiendo el modelo de una violencia doméstica indiferenciada que, por aquel entonces, incluía las relaciones afectivas, conyugales o no, y las relaciones paternofiliales. Es habitual atribuir ese primer «despiste» legislativo de ig89 -que se prolongaría durante mucho tiempo después- a la precipitación y la escasa reflexión con que se decidió esa reforma, a instancia del Grupo Socialista en el Senado, sin debate previo en el Congreso y sin una toma de conciencia de las complejas cuestiones que debía resolver la nueva regulación penal, en la que resultaba discutible -y discutido- desde la selección de los sujetos de tutela hasta la forma y el alcance de la protección propuesta ${ }^{3}$. Lo que se castigaba, con penas de prisión que fueron aumentando con los sucesivos cambios

\footnotetext{
${ }^{1}$ Sobre el contenido y la significación de ese Informe en el «descubrimiento» de esta forma de violencia en el Estado Español, Medina, JJ., Violencia contra la mujer en la pareja: investigación comparada y situación en España. Tirant lo Blanch, 2002, págs. 3I ss.

${ }^{2}$ Véase detenidamente este Informe, que tiene su origen en I986 cuando la Comisión de Derechos Humanos del Senado creó la Ponencia de Investigación de Malos Tratos a las Mujeres, en BOGG. Senado III Legislatura. Serie I. Boletín General, I2 de mayo de i989, 313.

${ }^{3}$ Ampliamente, Maqueda, ML., «La violencia habitual en el ámbito familiar: razones de una reforma. El Nuevo Derecho Penal Español», Estudios Penales en Memoria del Profesor Valle Múñiz, Aranzadi, 200I, págs. I5I5 ss.
} 
legislativos ${ }^{4}$, eran actos leves de violencia física habitual en el ámbito de la convivencia familiar.

Desde un principio, fueron manifiestas las razones del fracaso del modelo legislativo adoptado. Todas tenían que ver con su distanciamiento de la realidad que, supuestamente, se proponía regular. Por ejemplo, resultaba difícil de explicar que el legislador penal se propusiera reprimir la violencia en la pareja concentrando el objeto de tutela en la familia ${ }^{5}$, o que, desoyendo las recomendaciones del Informe de la Comisión del Senado, omitiera cualquier alusión a los casos de violencia psíquica, tan común y tan grave como la física y, a menudo, acompañante 6 , o que obviara situaciones complejas de conflicto entre no convivientes en casos reconocidos de riesgo, como los de separación conyugal ${ }^{7}$ o, finalmente, que dejara el elemento de la habitualidad a merced de una viciada interpretación judicial, estrictamente cuantitativa ${ }^{8}$...

El resultado fue un esperado vacío aplicativo de parte de nuestros tribunales, que garantizó durante años la impunidad de los agresores y la indefensión de sus víctimas. La Fiscalía General del Estado lo denunciaba en su Circular I/ı998, lamentándose de «la ausencia de pronunciamientos jurisprudenciales que aliviaran las dificultades del intérprete». A su juicio, el problema fundamental de su inaplicación práctica residía en «las dificultades interpretativas que se apreciaban en algunos de los preceptos o en algunos de los silencios del Código Penal al abordar la violencia doméstica y animaba a los Fiscales a actuar «supliendo con su investigación las deficiencias de prueba...». Y en I999, un estudio realizado por encargo del Consejo General del Poder Judicial sobre 5000 resoluciones había dado como resultado unas cifras que generaban «una impresión de ligereza y de lenidad» en el tratamiento judicial del problema, como destacaba Asúa9. Lo cierto es que, en los diez años siguientes a la entrada en vigor de aquella reforma de i989, un delito que se sabía frecuentemente cometido, hasta

${ }^{4}$ Pasando de la pena de uno a seis meses, bajo la regulación de I989 (art. 425), a la de seis meses a tres años bajo el Código penal de I995 (art. I53).

${ }^{5}$ Véase Asúa, A., «Los nuevos delitos de 'violencia doméstica' tras la Reforma de la LO II/2003, de 29 de septiembre», Cuadernos Penales Jose María Lidón I, 2004, Universidad de Deusto, págs. 202 ss.

${ }^{6}$ Como lo destacaba la Circular 2/I.990 de la Fiscalía General del Estado. Boletín del Información del Ministerio de Justicia, I5 de enero de I.99I, núm. I.586 y I.587. También, la Circular I/I.998. Pese a todo, no serían aceptadas las enmiendas que proponían la inclusión de la violencia psíquica en el proceso legislativo que condujo a la aprobación del texto del Código Penal de I995. Así, las del IU-IC (núm. 7I8), Grupo Mixto-ERC (nº. I5), Grupo Mixto UV ( ${ }^{\circ}$. I2) donde se afirmaba que «de no introducirse, la reforma no supondría ningún avance respecto a la legislación anterior y no serviría para resolver los problemas en el ámbito familiar» y la de IU-IC $\left(\mathrm{n}^{\circ}\right.$. $\left.7 \mathrm{I} 8\right)$ que proponía asimismo la inclusión diferenciada del «trato degradante». Véanse López Garrido, D./ García Arán, M., El Código penal de 1995 y la voluntad del legislador, I996, Madrid, pág. 95.

7 Así comenzaba la editorial «la violencia en cifras» de la revista Meridiana (Instituto Andaluz de la Mujer, I.997): «En las 52 semanas que hubo desde el I de enero al 31 de diciembre de I996, 50 mujeres, víctimas del terrorismo doméstico, fueron asesinadas. La mayoría, el 80 por ciento aproximadamente, estaban separadas». Sobre el sinsentido de esa exigencia, Laurenzo, P., «Los nuevos delitos de violencia doméstica: otra reforma precipitada», Revista Artículo 14, 2003, Mes de diciembre, Instituto Andaluz de la Mujer, pág. 7.

${ }^{8}$ Que exigían la interposición de denuncia para valorar las faltas concurrentes, que habían de ser más de tres y, además, prescindían de su toma en consideración, interrumpiéndose su cómputo, si las faltas denunciadas eran objeto de un juicio de condena, para no infringir el principio del non bis in idem. Más ampliamente, Cuenca I García, MJ., «La violencia habitual en el ámbito familiar», Revista Jurídica de Catalunya 4, I998, pág. 653.

${ }^{9}$ Véase, Asúa, A., 2004, pág. 224. Según datos del Consejo General del Poder Judicial, a los que años más tarde haría referencia Comas, «el 70\% de las denuncias se tramitaban como falta. Y sólo el 60\% de ellas acababa en un juicio, ya que muchas víctimas, en torno al $40 \%$ no acudían a la vista debido a que habían transcurrido dos o tres meses. Y en el $60 \%$ de los casos en los que sí se celebraba un juicio, todo terminaba en una absolución». Diario El País de I2 de diciembre de 2004, p. 36. Parecidas irregulares fueron denunciadas por la Asociación de Juristas THEMIS: «los jueces de instrucción tienden a calificar como faltas las agresiones físicas y verbales que se producen entre parientes, incluso cuando los hechos, por su gravedad son constitutivos de delito. El 3\% de las denuncias tramitadas como falta se refiere a agresiones físicas graves que deberían haberse considerado delito ... El delito de malos tratos habituales carece de aplicación práctica, a pesar de que el $50 \%$ de las víctimas refiere en su denuncia haber sufrido agresiones anteriores...». Consejo de la Mujer de la Comunidad de Madrid, Respuesta penal a la violencia familiar, págs. 89 y 90. 
ser capaz de generar una importante alarma social, apenas había sido penalmente perseguido ni castigado. Los medios de comunicación dieron buena cuenta de ello, sobre todo a raíz de la muerte de Ana Orantes en I997 que vino a poner de manifiesto, con toda nitidez, la inapropiada respuesta legal y del sistema de justicia penal ante el fenómeno de la violencia en la pareja. Las frecuentes manifestaciones y declaraciones que siguieron al caso y que se hicieron oír en distintos ámbitos, también parlamentarios, prepararon el camino para nuevas reformas legales ${ }^{\text {IO }}$.

Unas mejores y otras peores. Todas, presuntamente alentadas por el propósito de «dar respuesta a la situación de violencia que sufren muchas mujeres y a la demanda social provocada por esta violencia», tal como declaraba el Gobierno en el momento de elaborar, ya en I998, el primer Plan de Acción contra la violencia doméstica ${ }^{\mathrm{II}}$. En las nuevas regulaciones entraron, por fin, los casos de violencia psíquica o las parejas no convivientes y se acordó una definición de la habitualidad orientada a identificar los casos en que un clima de agresión permanente amenazara la seguridad de sus víctimas, cuya tutela iba a pasar a constituir uno de los objetivos preferentes de las sucesivas normativas penales a partir de la previsión de medidas de protección cautelares y acompañantes al juicio de condena. Pero, lo que pareció ser un primer intento de racionalizar la respuesta penal frente a la violencia en la pareja ${ }^{\mathrm{I} 2}$, iba a durar poco tiempo.

Muchas circunstancias fueron responsables de ese cambio de rumbo: unas legales, otras no. Empezando por estas últimas, no hay que perder de vista que, una vez reconocida públicamente la gravedad de esa violencia, crecieron los intereses en pugna para visibilizarla y sacarle rentabilidad política. Los diferentes actores sociales encontraron buenas razones para manipular la realidad de su existencia. Osborne se refiere a dos de ellos: de una parte, las instituciones, empeñadas en capitalizar el nuevo interés social hacia el problema y en dar la impresión de realizar política «feminista» desde el poder y, de otra, el propio feminismo, desmovilizado desde finales de los años ochenta, que se re-configura y se re-moviliza ganando más espacio social con la promoción de la denuncia del maltrato. La violencia contra las mujeres se había convertido en una cuestión política ${ }^{13}$.

La idea de primar la magnitud del problema iba a constituirse en una de las claves para mantener viva la conciencia social del mismo y asegurar la creciente intervención pública en su control. Por eso, cambia -y se amplía- la misma definición de violencia, haciéndose comprensiva de agresiones leves y ocasionales. Antes de que la ley penal II/2003 las declarara perseguibles como delito -y no sólo como falta- era constatable ya el esfuerzo institucional por incluirlas bajo el concepto de violencia de género, siguiendo esa tendencia general del feminismo por hacerlo extensivo a cualquier agresión contra la mujer ${ }^{14}$. Las Macroencuestas de 2000, 2002 o 2006, realizadas a nivel nacional por el Instituto de la Mujer para conocer cuántas mujeres eran víctimas de actos de maltrato en el ámbito doméstico son muy

\footnotetext{
${ }^{\text {Io }}$ Más detalles sobre las incidencias sociales que provocó el caso Orantes, en Medina, JJ., 2002, págs. 37 ss.

${ }^{\text {II }}$ Sobre este proceso legislativo, detalladamente, Morillas, «Respuestas del Código Penal ante la violencia doméstica. Propuestas de reforma», Estudios Penales sobre violencia doméstica, Editoriales de Derecho Reunidas, 2002, págs. 66I ss. Tras ese Plan, vendría otro (200I/2003), precedido por la denuncia de ineficacia en la persecución judicial de los hechos de maltrato. Son necesarios «más cambios normativos, para aumentar la protección de las maltratadas», se afirmaba desde Asuntos Sociales. Diario El País, de 15 de febrero de 200I, pág. 33.

${ }^{\mathrm{I} 2}$ Sobre la reforma operada por la L.O. ı4/ı999, de 9 de junio y las medidas que incorporó en el tratamiento de la violencia en la pareja, ampliamente, Maqueda, ML., 200I, págs. I5I6 ss.

${ }^{13}$ Casi literalmente, Osborne, R., «De la 'violencia' (de género) a las 'cifras de la violencia': una cuestión política», Empiria (Revista de Metodología de Ciencias Sociales) I4, julio-Diciembre 2007, págs. 3, 6.

${ }^{14}$ Se refiere a esa tendencia -ya generalizada- a ampliar el concepto de violencia de género desde el maltrato habitual a actos concretos de poder y control, Hageman-White, C., Understanding and challenging gender violence: Implications of a human rights perspectiva for theory and practice. Equality is not a Utopia, Women's Worlds/Aranzadi, 2008, pág. I04.
} 
indicativas de ese afán indiferenciador a que me refiero. Especial consideración merece la noción de «maltrato técnico» que emplean a partir del concepto de «violencia estructural» acuñado en 2000 por el Consejo de Europa para designar esa violencia invisible, imperceptible que está presente en la sociedad y en sus estructuras de poder ${ }^{15}$. Algunas de las trece cuestiones planteadas en esas Macroencuestas tenían que ver con ella: «¿decide las cosas que Vd puede o no hacer?; ¿no tiene en cuenta sus necesidades?; ¿ironiza o no valora sus creencias (ir la iglesia, votar a algún partido, pertenecer a alguna organización)?; ¿no valora el trabajo que realiza?...». Contestar afirmativamente a alguna de ellas, con un «frecuentemente» o «a veces», significaba ser una mujer «técnicamente» maltratada, pese a carecer de autoconciencia. La etiqueta la ponía el Instituto de la Mujer. No es de extrañar que, utilizando los datos provenientes de esas mismas fuentes, Amnistía Internacional afirmara en 2006, que entre I.800.000 y 2.000.000 mujeres sufren violencia de género en el Estado español, unas cifras de dudosa fiabilidad si se tiene en cuenta que son comprensivas de actos de abuso psicológico como los descritos o quizás otros de carácter físico que, por su escasa entidad, sólo pueden ser catalogados como «actos de maltrato», a partir de un concepto peligrosamente extensivo de violencia ${ }^{\mathrm{i} 6}$.

Ese nuevo concepto «omnicomprensivo» de violencia llegó a la ley penal en 2003. Fue a partir de su ampliación a los malos tratos y las amenazas leves con armas en el ámbito doméstico. Una improvisada predicción del Consejo General del Poder Judicial, conocida un par de año antes, sirvió de coartada al legislador penal para valorar esos hechos, por poco importantes y aislados que fueran, como el origen de una violencia grave y continuada, que es la que supuestamente se trataba de combatir: «la experiencia acumulada en los últimos años, afirmaba el Consejo, demuestra que, con frecuencia, las primeras agresiones que se producen en una misma familia, sólo en apariencia desprovistas de gravedad, llevan en sí el germen de la violencia, de una violencia moral que algunas veces tiene un reflejo físico evidente pero que, incluso en aquellas otras en que no se materializa en forma de golpes o lesiones, comporta una gravedad intrínseca apreciable, cuyas nefastas consecuencias se acaban manifestando con el tiempo...». Seguir tratándolas como leves -y constitutivas de falta- «no serviría para frenar la progresión cuantitativa y cualitativa de las acciones violentas en el seno familiar, ni coadyuvar a la erradicación de las causas que la originan.... ${ }^{17}$.

No puede decirse, sin embargo, que esa decisión expansiva del legislador de 2003 siguiera una línea continuista -más o menos cómplice- con las campañas institucionales abiertamente combativas frente al maltrato en la pareja o, más genéricamente, frente a la violencia contra las mujeres. Más bien parece que las utilizó como pretexto para hacer llegar su reconocida vocación punitivista a un amplio ámbito de relaciones -domésticas o cuasidomésticas ${ }^{18}-$ marcadas por el común denominador de la vulnerabilidad de sus víctimas.

\footnotetext{
${ }^{15}$ Esa «violencia estructural» se identifica como una forma de violencia -distinta de la física, la sexual, la económica, la psicológica o la espiritual- que «comprende barreras no visibles e intangibles para la realización de las opciones potenciales y derechos básicos de la mujer. Estos obstáculos se arraigan y se reproducen a diario en el mismo tejido de la sociedad, es decir, en las diferencias de poder y las relaciones de poder (estructuras) que generan y legitiman la desigualdad». Apéndice II a la Recomendación $n^{\circ} \mathrm{R}$ (2002) 5 del Comité de Ministros del Consejo de Europa sobre la Protección de las Mujeres contra la Violencia. Instituto de la Mujer, 2002, pág. 87.

${ }^{16}$ El planteamiento y los datos, con similares conclusiones en Osborne, R., 2007, págs. I2 Ss. Sobre los resultados de la última macroencuesta de 2006, más extensamente Evaluación de la aplicación de la Ley Orgánica I/2004 de 28 de diciembre. Medidas de Protección contra la violencia de género. Ministerio de Igualdad, 2008, págs. 292 ss.

${ }^{17}$ Informe del Consejo General del Poder Judicial, acordado en el Pleno de 2I de marzo de 200I, p.I6. Una visión crítica que comparto en Laurenzo, 2003, págs. 838 ss.

${ }^{18}$ Todavía hoy descritas en el artículo I73,2 CP, que incluye relaciones no sólo conyugales o de afectividad análoga y estrictamente familiares ascendientes, descendientes o hermanos), sino también relativas a personas «amparadas en cualquier otra relación por la que se encuentren integradas en el núcleo de convivencia familiar» o que «por su especial vulnerabilidad se encuentren sometida a custodia y guarda en centros públicos y privados».
} 
Una vez más, se había puesto de manifiesto el desencuentro entre la ley penal y la realidad de la violencia de género, con un primer efecto inadmisible, que acabaría condicionando el futuro de sus relaciones: el de identificar a la mujer en la pareja como un ser vulnerable ${ }^{\mathrm{r} 9}$. Sirva como ejemplo de esa victimización impuesta a la mujer, su obligatorio sometimiento a una pena de alejamiento, que le impediría durante años reanudar la convivencia, a veces deseada, con su agresor ${ }^{20}$. Por otra parte, la práctica iba a demostrar muy pronto que la urgencia por criminalizar con penas, a veces desproporcionadamente elevadas, actos leves de maltrato desincentivaría a los tribunales a investigar las situaciones graves de violencia que podían quedar escondidas detrás de la primera denuncia de malos tratos, consolidando una inercia judicial perversa y peligrosa para la seguridad de las mujeres ${ }^{21}$. Lo pronosticó Laurenzo en 2004, cuando afirmaba que «si las dificultades derivadas de la tramitación de los hechos como falta no convencieron a los operadores del Derecho sobre la necesidad de indagar a fondo en la auténtica magnitud de la violencia escondida detrás de una primera denuncia, ¿qué cabe esperar ahora que la ley les facilita la aplicación de penas de prisión y medidas cautelares contundentes -incluida la prisión provisional- ante un episodio único de maltrato ocasional? No es difícil pronosticar que este cambio legislativo condena a una función casi residual al delito de violencia habitual...que cederá todavía más terreno a la antigua falta de malos tratos hoy convertida en delito» ${ }^{22}$.

La Ley I/2004, que abrió un nuevo periodo legislativo, iba a heredar -e incrementar- buena parte de esos lamentables desaciertos. No es casualidad que se le haya atribuido a ella y no a la regulación precedente esa polémica medida de convertir las faltas de malos tratos en delito y que en la conciencia general persista la idea de que su puesta en marcha resultó ser conflictiva precisamente por haber coincidido con la presentación de varias cuestiones de inconstitucionalidad, unas por su eventual contradicción con el principio de proporcionalidad sancionadora penal ${ }^{23} \mathrm{y}$ otras por el desconocimiento de la

\footnotetext{
${ }^{19}$ Así, con amplias referencias bibliográficas, Maqueda, ML., «La violencia de género: entre el concepto jurídico y la realidad social», Revista Artículo 14, Instituto Andaluz de la Mujer, 2006, pág. 2.

${ }^{20}$ Fue obra de la ley $15 / 2003$, de 25 de noviembre que reformó en ese sentido el artículo 57,2 CP. Denunciaba ese efecto victimizador inaceptable una de las primeras sentencias que conoció del problema: «el Tribunal considera absolutamente improcedente que se adopten medidas de protección de la víctima ... en contra de la voluntad expresa de la propia víctima, cuando ésta es una persona adulta y dotada de plena capacidad de obrar, a la que hay que suponer en plenitud de facultades mentales y en condiciones de juzgar sobre sus propios intereses ... Otra cosa sería tratar a las víctimas de la violencia de género como sujetos cuya capacidad de autodeterminación se encuentra abolida o limitada y cuyo interés ha de ser, por tanto, tutelado institucionalmente por encima de su propia opinión, al modo de los menores o incapaces, lo que francamente nos parece ofensivo para la dignidad personal de la víctima que precisamente se pretende proteger» Considerando 4 de la Sentencia de la Sección 4 a de la Audiencia Provincial de Sevilla de I5 de julio de 2004.

${ }^{21}$ Entre otras razones, porque la práctica ha demostrado que las agresiones se hacen más graves tras la denuncia presentada por la víctima. De la Cuesta, JL., «Ciudadanía, sistema penal y mujer», Estudios Penales en Homenaje a Enrique Gimbernat, T.I. Edisofer, 2008, pág. 20I.

${ }^{22}$ Laurenzo, P., «Los nuevos delitos de violencia doméstica: otra reforma precipitada», Serta. Homenaje a Alexandri Baratta, Salamanca, 2004, pág. 840.

${ }^{23}$ (ATC 233/2004 y 332/2005). Se refiere a esa confusión, Larrauri, E., Criminología crítica y violencia de género. Trotta, 2007, pág. 87. Sobre el contenido de esas cuestiones y la decisión del Tribunal Constitucional de inadmisión por entenderlas notoriamente infundadas, véase el completo análisis y las conclusiones de González Cussac, JL., 2007. La intervención penal contra la violencia de género desde la perspectiva del principio de proporcionalidad. Gómez Colomer (coord.), Tutela procesal frente a hechos de violencia de género, Universitat Jaime I, págs. 457 ss.
} 
voluntad de la víctima en la adopción de medidas de protección ${ }^{24}$. Aunque no iban a ser las únicas.

\section{Segundo Periodo (2004-2008)}

Es genéricamente reconocido en la doctrina penal que el mayor acierto de la ley I/2004 es la perspectiva integral con que aborda el problema de la violencia en la pareja ${ }^{25}$. Y su mayor desacierto, entienden muchos, haberse declarado una ley de género, abandonado la perspectiva doméstica de las anteriores propuestas legislativas ${ }^{26}$. Claro que, por serio que sea el recelo que esa decisión política criminal pueda suscitar, hay razones de coherencia que la amparan. Si el problema que se afirma preocupante, con ayuda de cifras y de una alarma social creciente, más o menos inducida, es la violencia contra la mujer, ¿por qué esos reiterados intentos de disimularla en el contexto neutro -y disperso- de las relaciones familiares o aún asimiladas ? $^{27}$. Cuestiones bien distintas son esas otras que nos pueden llevar a valorar -críticamente- a esta ley: en particular, si puede proponerse como una ley de género, cuando abandona la atención a otras mujeres del entorno doméstico y social e incluye a seres vulnerables «asexuados» ${ }^{28}$, o también, si ha cumplido de modo adecuado con su objetivo de proteger a las mujeres, siendo así que reserva su capacidad disuasoria penal casi exclusivamente para los actos leves de maltrato físico y psíquico o contra la libertad en el ámbito de las relaciones afectivo-sexuales y prima una intervención punitiva de oficio- y sin participación de la mujer a la hora de proponer soluciones a los conflictos de la violencia en la pareja $^{29}$.

Seguramente se han confundido unas y otra valoraciones. En mi opinión, no es la perspectiva de género -tan polémica- la que hace criticable la ley sino, precisamente, la ausencia de la misma. O mejor, quizás, la ausencia de una perspectiva de género asumible. Quisiera plantear, en esa línea, dos cuestiones importantes: ¿por qué la violencia que visibiliza la ley -como violencia de género- es la de sus manifestaciones menos relevantes,

${ }^{24}$ Donde se reclamaba la necesidad de tomar en consideración la perspectiva de la mujer, en la idea común de que ignorarla, otorgándole una protección que no quiere «es persistir en el mito de que es incapaz de decidir por sí misma», permitiendo que pase «de estar sometida al maltratador a estarlo al Estado». Me refiero al Auto I67/2005, de 20 de mayo de la Sección 4 a de la Audiencia Provincial de Valladolid y al I36/2005, de 29 de junio del Juzgado de lo Penal $\mathrm{n}^{\circ} 20$ de Madrid, con sendas cuestiones de inconstitucionalidad, a la que se suma la planteada el I5 de junio de 2006 por la Sección $2^{a}$ de la Audiencia Provincial de Lleida, recientemente resuelta por el Tribunal Constitucional, como veremos más adelante.

${ }^{25}$ Por todos, recientemente, De la Cuesta, 2008, pág. 209. El Preámbulo de la ley describe su ámbito refiriéndose «tanto a los aspectos preventivos, educativos, sociales, asistenciales y de atención posterior a las víctimas, como a la normativa civil que incide en el ámbito familiar o de convivencia donde principalmente se producen las agresiones» $\mathrm{y}$, desde luego al penal.

${ }^{26}$ Véase en Boldova, MA,/Rueda,MA., «Consideraciones político-criminales en torno a los delitos de violencia de género», La reforma penal en torno a la violencia doméstica y de género, Atelier, 2006, págs. I8 ss. Sobre los intentos de fundamentación de bienes jurídicos adicionales en la violencia en la pareja, críticamente Acale, M., 2006, págs. I49 ss. Una visión general de las objeciones al derecho penal de género, en Alonso Álamo, M., «Protección penal de la igualdad y derecho penal de género», Cuadernos de Política Criminal 95, 2008, págs. 30 ss.

${ }^{27}$ Como han hecho las leyes de reforma precedentes. Así, Faraldo, P., «Razones para la introducción de la perspectiva de género en Derecho penal a través de la LO I/2004, de 28 de diciembre, sobre medidas de protección integral contra la violencia de género», Revista Penal I7, 2006, págs. 76, 77. Sobre esa pretensión de neutralidad, críticamente, Añón, MJ./Mestre,R., «Violencia sobre las mujeres: discriminación, subordinación y Derecho», Boix/Martínez (coord.), La nueva ley contra la violencia de género, Iustel, 2005, págs. 46 ss.

${ }^{28}$ Críticamente, con razón, Larrauri, 2007 , págs. 98 ss. y Mestre, R., La caixa de Pandora. Introducció a la teoria feminista del dret, 2006 , págs. 152, 153.

${ }^{29}$ En su momento, intenté buscar explicaciones razonables, por lo menos, a la primera de esas respuestas insatisfactorias de la ley. Maqueda, «La violencia contra las mujeres: una revisión crítica de la ley integral», Revista Penal I8, 2006, págs. I76 ss. 
hasta un punto en que cabe dudar si son indicativas de esa situación estructural de subordinación y discriminación que dice proponerse combatir?. O, también, ¿por qué una ley llamada a proteger a las mujeres, lo hace sin contar con ellas?. Veámoslas.

El siempre discutido recurso a leyes sexo-especificas, como las llaman Añón y Mestre, necesita un mayor esfuerzo de justificación cuando se proponen combatir la discriminación en un contexto estrictamente punitivo ${ }^{30}$. El Tribunal Constitucional lo ha planteado recientemente en términos de «razonabilidad», argumentando la existencia de una mayor lesividad en la violencia que los hombres ejercen contra la mujer en la pareja, para poder así legitimar la existencia de una agravación penal en esos casos. Existe, en su opinión, un efecto añadido a los propios del uso de la violencia en otro contexto, que aquí se expresaría en un daño a la seguridad, a la libertad y a la dignidad de la mujer, como consecuencia de los ingredientes de temor y de menosprecio que son inherentes a los atentados de género: «no resulta irrazonable entender, dice el Tribunal Constitucional, que en la agresión del varón hacia la mujer que es o fue su pareja se ve particularmente dañada la libertad de ésta (porque la consolidación de la discriminación agresiva del varón ...añade un efecto intimidatorio en la conducta que restringe las posibilidades de actuación libre de la víctima); se ve intensificado su sometimiento a la voluntad del agresor y se ve particularmente dañada su dignidad, en cuanto persona agredida al amparo de una arraigada estructura desigualitaria que la considera como inferior, como ser con menores competencias, capacidades y derechos a los que cualquier persona merece $»^{3 \mathrm{I}}$. De este modo, ha respondido a las numerosas cuestiones de inconstitucionalidad que le habían sido presentadas en relación a los preceptos de la ley integral que sancionan más gravemente al hombre - por el hecho de serlo- cuando agrede levemente a una mujer, en el marco de una relación de pareja ${ }^{32}$.

No me propongo objetar nada a ese discurso de género, que no sea su dudosa aplicabilidad a las agresiones ocasionales consistentes en atentados leves a la integridad y la libertad de la mujer, que son las que han provocado estos últimos pronunciamientos constitucionales. Y, básicamente, porque entiendo que, en una gran mayoría, se trata de actos que no llegan a superar el umbral de la violencia y se limitan a ser meros «indicadores» de una estructura social sexista, como la existente. La expresión de «micromachismos», acuñada por Bonino, serviría quizás para designar esas microviolencias consistentes en pequeños controles y abusos de poder -incluido algún maltrato esporádico-, que podrían tener cabida en los preceptos cuestionados ${ }^{33}$. En ellos, ese ingrediente de género que se mide en términos de agresiones instrumentales de

\footnotetext{
${ }^{30}$ Hablan de subordinación Añón,MJ../Mestre,R., 2005, págs. 56 ss. Sobre la afirmación del texto que sugiere la necesidad de adecuarse a las exigencias más estrictas del Derecho penal, ampliamente, Laurenzo , «La violencia de género en la Ley Integral: valoración político.criminal», Jueces para la Democracia 54, 2005, págs. 29 Ss. También, Alonso Álamo, M., 2008, págs. 22 ss.

${ }^{31}$ Véase el apartado 9 A) de la sentencia del Tribunal Constitucional 59/2008, de I4 de mayo de 2008. Sorprende que al inicio de esta sentencia (apartado 7) se afirme que «no es el género -dice el sexo- el factor exclusivo o determinante de los tratamientos diferenciados...», en un claro intento de eludir plantear la violencia contra la mujer como un trato discriminatorio, relacionándolo con el menos problemático principio de igualdad. En parecidos términos se manifiestan las SSTC 76/2008, de 3 de julio; 80, 8I, 82/2008, de I7 de julio; 95, 96, 97, 98, 99 y 100/2008, de 27 de julio de 2008. A favor de esa línea jurisprudencial, Villacampa, C., «La violencia de género: aproximación fenomenológica, conceptual y a los modelos de abordaje normativo», págs. 80 ss. Críticamente, sin embargo, Acale,M., «Análisis del Código penal en materia de violencia de género contra las mujeres desde una perspectiva transversal», págs. II7 ss. Ambos en Violencia de género y sistema de justicia penal, Universitat de Lleida/Tirant lo Blanch, 2008.
}

${ }^{32}$ Me refiero, en particular, a los artículos I53, I7I,2 y I72,2 que prevén un incremento de pena de tres meses en su límite inferior, cuando «la ofendida sea o haya sido esposa, o mujer que esté o hay estado ligada a él por análoga relación de afectividad, aún sin convivencia». Es de tener en cuenta que ninguna cuestión de inconstitucionalidad se ha planteado en relación a atentados más relevantes (lesiones graves), donde la agravante de género también está presente, como en el artículo I48, 4 CP.

${ }^{33}$ Sobre este planteamiento, Osborne, 2007 , págs. I8 ss. 
sometimiento e intimidación -tal como lo describe el propio Tribunal Constitucional-, estará muy a menudo ausente ${ }^{34}$.

Poco parecen importar las graves consecuencias que está teniendo en la práctica este nuevo distanciamiento del legislador penal de la realidad de la violencia de género. Como resultado de la extensión de su concepto a cualquier agresión esporádica en la pareja y de las insistentes campañas institucionales de alarma y concienciación social en favor de su denuncia, se han hecho evidentes graves disfunciones en la respuesta judicial y policial a la avalancha de casos que se les presentan.

Los medios de comunicación dan cuenta, a menudo, de esa insatisfactoria realidad: juzgados que están colapsados y jueces desbordados por la sobrecarga de asuntos ${ }^{35} \mathrm{o}$ insuficiencia de agentes policiales que controlen las medidas de protección decretadas frente a las cuantiosas denuncias por actos de maltrato ${ }^{36}$. Y, lo que es más importante, mujeres en grave situación de riesgo, que viven en un clima persistente de hostilidad y amenaza, y que quedan invisibilizadas y confundidas bajo esa llamada indiferenciada a una violencia de género que etiqueta todo por igual: tanto si es un brote agresivo en un conflicto puntual de pareja, como si se trata de una manifestación duradera de una situación de opresión y dominio ${ }^{37}$. Ellas son las verdaderas víctimas de la desatención judicial e institucional. Lo plantea Sáez desde su experiencia en uno de los juzgados de Madrid: parece «como si ese fenómeno más grave, el de mayor impacto y capacidad de destrucción de la personalidad de la mujer... hubiera desaparecido. Posiblemente sea una consecuencia de la estrategia de criminalizar todo el conflicto familiar, hasta la coacción leve, lo que haya generado que se desatienda a la violencia permanente.... ${ }^{38}$.

Una ausencia individualizada de tutela, que se ve agravada cuando las víctimas de esa violencia son inmigrantes ilegales, que pasan a ser en la práctica «institucionalmente invisibles», en expresión de Pérez Machío, a causa de un interés preferente en el control de su situación administrativa por encima de la necesidad de detectar y evitar su victimización ${ }^{39}$. Aunque pudiera parecer lo contrario. El recientemente aprobado «Plan de Atención y prevención de la violencia de género de la población inmigrante» se ha propuesto, según sus propios términos, combatir «las resistencias relevantes en las mujeres

\footnotetext{
${ }^{34}$ Otra cuestión es que, fruto de la arbitrariedad judicial, esos preceptos alberguen casos relevantes de violencia física, de intimidación o de coacción. Véanse algunos ejemplos jurisprudenciales de estos últimos en Maqueda, 2006, págs. I8I, I82.

${ }^{35}$ Una realidad que se puso de manifiesto muy tempranamente. Un año después de la entrada en vigor de la Ley integral ya se hablaba de saturación de los juzgados especializados en violencia. Diario El País, de 25 de junio de 2006 , p. 43. Hoy, la denuncia continúa. En 2008, varios jueces se quejan ante la prensa de la sobrecarga de asuntos. Véase, por ejemplo, Diario El País de ir y 26 de noviembre, pp. 36 y io, respectivamente.

${ }^{36}$ Los sindicatos policiales se quejan de la insuficiencia de medios y de personal especializado. «La seguridad de 25.000 víctimas de violencia machista está en manos de 54I agentes especializados...» dice el Diario El País de 24 de agosto de 2008 , pág. 37.

${ }^{37}$ Mujeres en situación de «riesgo extremo», como se denominaban en esa crónica del Diario El País de 24 de agosto de 2008 , p. 37. Tiene razón Larrauri, 2007 , cuando afirma que es, en su caso, caracterizado por «un uso sistemático de la violencia, amenaza de violencia y otros comportamientos y tácticas coactivas, destinadas a ejercer el poder, inducir miedo o controlar» donde resulta manifiesta esa ideología de género que resulta tan destructiva para la mujer, págs. $42 \mathrm{ss}$

${ }^{38}$ Sáez, R., «Una crónica de tribunales. La justicia penal en la estrategia de la exclusión socia»l, Jueces para la Democracia 58, 2007, pág. I6.

${ }^{39}$ Que crece cada año. En los datos que aporta la Fiscalía General del Estado en 2008, el número de mujeres extranjeras (irregulares?) asesinadas en el año precedente fueron 32 de un total de 75. Memoria. Vol. I. Ministerio de Justicia, p. 49I. Véase el interesante estudio y las esclarecedoras conclusiones de Pérez Machío, AI., «La protección de la mujer inmigrante irregular, víctima de violencia de género a partir de la Ley Orgánica I/2004, de 28 de diciembre, de protección integral contra la violencia de género», Puente (dir.) Criminalidad organizada, terrorismo e inmigración, Retos contemporáneos de la política criminal, Comares, 2008, págs. 315 y 325 ss.
} 
extranjeras para el acceso a los recursos» por el recelo y la desconfianza que sienten ante los Cuerpos y Fuerzas de Seguridad y otras instituciones públicas ${ }^{40}$. Lo que no aclara el nuevo Plan es que, pese a sus «buenas intenciones» formativas, informativas y de sensibilización en favor de estas víctimas de la violencia de género, se trata de un temor fundado, ya que esas mujeres maltratadas, para optar a tales recursos y evitar el expediente de expulsión, deben denunciar y, además, obtener una orden de protección y una sentencia condenatoria, por imperativo de la orden $\mathrm{i} 4 / 2005$, que sigue en vigor. Así se explica que, ante la espada de Damocles de ser finalmente expulsadas, «no osen acercarse a las comisarías», como señala Naredo ${ }^{4 \mathrm{~T}}$.

Pero lo cierto es que los conflictos que la ley integral ha planteado en la práctica acaban afectando a todas las mujeres. La idea de que la agresión contra ellas es un asunto público se ha llevado a sus últimas consecuencias hasta llegar a privarles del control de sus necesidades y de la autonomía de sus decisiones vitales. Manifestaciones de esa colonización legal son la persecución de oficio de estos delitos, la imposibilidad de retractarse de una denuncia previa o la obligación de acatar órdenes de alejamiento e incomunicación no deseadas, pudiendo llegar a verse incriminadas en un procedimiento penal por complicidad en un delito, como el de quebrantamiento de condena ${ }^{42}$.

Una vez más se pone en evidencia la desconexión entre la realidad empírica y la legalidad vigente. La práctica judicial ha demostrado que un alto porcentaje de mujeres no denuncian ${ }^{43} \mathrm{o}$ si lo hacen, no declaran después en contra de su agresor (amparándose en la excepción procesal del art. 4I 6 LECr,, que les exime de ese deber) o aún se retractan en juicio, motivando muchas veces una sentencia absolutoria. No deja de ser común, también, la complicidad de las mujeres en la desobediencia a las órdenes de alejamiento decretadas judicialmente contra sus agresores.

El informe de 2007 del Observatorio estatal de violencia contra la mujer se refiere a un $62,86 \%$ de denuncias frustradas por la renuncia de la mujer durante el juicio ${ }^{44}$. Un porcentaje similar ofrece Sáez en las conclusiones de su estudio de campo: En «el 64,6 de la muestra, las mujeres no colaboraban. Demandaban ayuda en un primer momento, comprobaron cómo funciona la justicia penal...y desconfiaron del sistema de manera radical, lo que expresaban acogiéndose a la excepción del secreto familiar o, para tratar de remediar las consecuencias del proceso, se retractaban de lo antes dicho, incluso arriesgándose a ser perseguidas penalmente, o emitían una declaración hostil a las pretensiones del acusador oficial» ${ }^{45}$. En definitiva, razones que tienen que ver con «la tradicional desconsideración hacia la víctima que ha mostrado siempre el sistema penal»o el característico «acoso procesal», a los que se refiere Larrauri. En su artículo «¿Por qué

\footnotetext{
${ }^{40}$ Como se contempla literalmente en su «Justificación», 2009, págs. 4 Ss.

${ }^{41}$ Véase la información contenida en el Diario El País, de so de enero de 2009, un día después de la aprobación del Plan, p. 35 .

${ }^{42}$ Véanse las consideraciones de Faraldo en relación a la imputación automática de este delito y a las disfunciones que provoca, asimismo, en el ámbito de la suspensión de la pena. «Tendencias de política criminal en el control penal de la violencia de género: alternativas a la privación de libertad y vicisitudes de la ejecución de la pena de prisión para condenados por violencia de género», Puente/Ramos (coord.) Política criminal y reformas penales. Tirant, 2007 , págs. 56 ss. También, Cid Moliné, «Penas no privativas de libertad en la Ley Orgánica I5/2003», Revista de Derecho y Proceso Penal I2, 2004, pág. 227.

${ }^{43}$ Haimovich,P., «El concepto de los malos tratos. Ideología y representaciones sociales», Maqueira/Sánchez (comp.), Violencia y sociedad patriarcal, Madrid I99०, apunta alguna hipótesis cuando afirma, como resultado de su estudio, que «la mujer que denuncia es vista como sometida a una situación tensionante en la que no sólo pone en evidencia a su cónyuge sino que se pone en evidencia a ella misma, su debilidad, su humillación, su degradación, su fracaso o frustración en la consecución de su 'ser mujer'...».

${ }^{44}$ Informe anual del Observatorio estatal de violencia contra la mujer, 2007, pág. I87

${ }^{45}$ Sáez, R., 2007, pág. I4.
} 
retiran las mujeres maltratadas las denuncias?», esta autora incorpora nuevos motivos, igualmente relevantes, como la falta de apoyo económico o el temor a represalias ${ }^{46}$.

Aunque no dispongo de cifras, es también reconocida la elevada proporción de mujeres que consienten o aún propician la aproximación de su agresor. En uno de los seminarios de fiscales delegados en violencia contra la mujer, en noviembre de 2006 , se denunciaba con preocupación este hecho: «Viene sucediendo con frecuencia en la práctica diaria que, llegado el momento de la ejecución de tales penas, los implicados -víctima y condenado- han reanudado su convivencia, y los órganos judiciales no pueden modificar, anular ni dejar sin efecto, las penas accesorias impuestas». No hay una propuesta unívoca de solución entre los operadores jurídicos pero sí una genérica unanimidad en exculpar, en todo caso, a la mujer. Al principio fueron argumentaciones relacionadas con un ficticio error de prohibición excluyente de la culpabilidad y, más adelante, la petición de indulto parcial con suspensión del resto de la pena, una estrategia propuesta por la Fiscalía General del Estado que ahora ha cedido en favor del principio de oportunidad, acordando no deducir testimonio contra la mujer en los casos de cooperación o inducción al quebrantamiento ${ }^{47}$. Seguramente sea la opción más eficaz, una vez que la jurisprudencia penal se ha distanciado de ese primer pronunciamiento judicial que pareció reconocer carácter disponible a la medida de alejamiento, cuando afirmó que «la reanudación de la convivencia acredita la desaparición de la circunstancias que justificaron la medida de alejamiento, por lo que ésta debe desaparecer y quedar extinguida $\wedge^{48}$. Pero, sobre todo, después que el Tribunal Constitucional ha dejado intacto su carácter de «norma de orden público», en una reciente sentencia que ha frustrado las esperanzas de muchos ${ }^{49}$.

Si alguna conclusión es posible, a partir de una toma de conciencia de las conflictivas situaciones a que conduce el desconocimiento de la voluntad de la víctima, es la de reflexionar acerca de una línea de actuación distinta, desde el estado, que no potencie la intervención penal ni, por tanto, el deber de denunciar de las mujeres. En definitiva, romper con el signo represivo de la ley integral -que, por ejemplo, prohíbe siempre la mediación ${ }^{50}$ o condiciona sus recursos asistenciales a la denuncia penal ${ }^{5 \mathrm{st}}-\mathrm{y}$ de las campañas institucionales que lo refuerzan, sobre la base de no ofrecer más soluciones al maltrato que las que pasan por el proceso, despreciando los efectos beneficiosos que puede aportar el recurso a vías socio-terapéuticas para desactivar los mecanismos de opresión y alienación que sufren las mujeres, en la línea propuesta por muchas profesionales de esos ámbitos ${ }^{52}$.

${ }^{46}$ Larrauri, E., en Revista de Derecho Penal y Criminología, 2003, págs. 277 y ss. Sobre la desconsideración a que se refiere la autora, cabe ejemplificar con la actitud de los órganos llamados a recibir las denuncias y proteger a las víctimas. Una crónica muy representativa en el Diario El País de 3 de julio de 2008, bajo el Título: «Si le acosa, ¿por qué no cambia de teléfono?», pág. 39.

${ }^{47}$ Como se hace constar en la Memoria de la Fiscalía General del Estado, 2008, Vol I, pág. 50I.

${ }^{48}$ SAP. Sevilla Secc. $4^{a}$, de I5 de julio de 2004 (p. de Paúl Velasco), después confirmada en su doctrina por la STS de 26 de septiembre de 2005 (p. Giménez García). Sobre ella y otros pronunciamientos interesantes, véase Valeije, I., «Penas accesorias, prohibiciones del art. 48,2 del CP y delito de quebrantamiento de condena. Consideraciones críticas sobre el art. 57,2 del CP.», Estudios penales y criminológicos 26, 2006, Santiago de Compostela, págs. 322 y ss. Esta línea interpretativa se ha visto frustrada por otros pronunciamientos jurisprudenciales que declaran la no disponibilidad de esa medida penal. Así la STS. 775/2007, de 28 de septiembre.

${ }^{49}$ Alegando defectos formales para inadmitir una de las cuestiones de inconstitucionalidad que le había sido planteada por la Sección $2^{a}$ de la Audiencia Provincial de Lleida con fecha I5 de junio de 2006 . Véase la STC. I4I/2008, de 30 de octubre de 2008, con el voto particular de magistrado Pérez Tremps.

${ }^{50}$ Véase el detallado análisis de Esquinas,P., 2008, Mediación entre víctima y agresor en la violencia de género, Tiranto lo Blanch/Universidad de Granada, págs. 25 ss.

${ }^{51}$ Se refiere a ambas cosas y las matiza , Larrauri, E, 2007, págs. 66, I04, I05.

${ }^{52}$ Osborne, R., 2007, págs. I8, 26. También, Villavicencio, P., «Barreras que impiden la ruptura de una situación de maltrato», Osborne (coord.), La violencia contra las mujeres. Realidad social y políticas públicas, Madrid, 200I, págs. 47,48 . 
Lo más lamentable es que, mientras con pesimismo se intenta evaluar el dudoso acierto de las decisiones politico-criminales adoptadas por la ley integral para afrontar la realidad de la violencia en la pareja ${ }^{53}$, se siguen haciendo propuestas maximalistas en favor de la idea de incrementar todavía la vía punitiva. No faltan voces, desde el feminismo institucional, que buscan reforzar las actuales medidas represivas con otras como «el cumplimiento efectivo de las medidas de protección de las víctimas y el cumplimiento íntegro de las penas», «la tipificación del delito de terrorismo sexista para todos los actos de violencia ejercitados por los hombres contra las mujeres, sus hijos e hijas o sus familiares más allegados», «la supresión judicial sistemática de todo comunicación del causante para con sus hijos» o «la introducción de un delito de apología del terrorismo sexista para perseguir todas aquellas actitudes, comentarios y sarcasmos que obedezcan al propósito de minimizar o desalentar a las víctimas en su decisión de denunciar ante los tribunales» ${ }^{54}$.

Las posibilidades de prosperar de estas peticiones dirigidas a los poderes del estado son inciertas por el momento. Mucho más que los últimos intentos de impedir la retirada de las denuncias por parte de las mujeres maltratadas, suprimiendo la exención legal de declarar contra la pareja, a las que se acogen un 37\% de la mujeres, después de una denuncia previa (art. 4I6 LECr). En el último informe del Observatorio Estatal sobre la violencia contra la mujer se defiende que, con el reconocimiento de ese derecho a la mujer, «se está dando entrada, en presencia de delitos perseguibles de oficio, al perdón del ofendido cuya única finalidad es la de conseguir la impunidad de los presuntos autores de tan execrables conductas, deviniendo, por tanto, absolutamente ineficaz la protección legal a la víctima» ${ }^{55}$. De poco vale argumentar con los riesgos que, en nombre de esa protección impuesta, deben asumir entonces las mujeres que declaran en falso o se niegan a declarar, de ser incriminadas por los delitos de desobediencia o de falso testimonio ${ }^{56}$.

A veces se ignora, no se si interesadamente, que el género se construye también discursivamente desde el Derecho, reproduciendo el sistema de dominio que se dice combatir. Por eso es tan importante denunciar las leyes sobre violencia en la pareja que controlan a las mujeres, las victimizan, infantilizan o les quitan poder de decisión y agencia, porque, como señalan Añón y Mestre, alimentan la idea «de que realmente las mujeres somos seres necesitados permanentemente de tutela masculina o estatal y, por tanto, no somos seres iguales ni autónomos (tesis patriarcal que queríamos combatir)» ${ }^{57}$.

\footnotetext{
${ }^{53}$ Faraldo, 2007, habla de «fracaso», en cuanto a la forma de «entender y atender la propia ambivalencia que manifiesta la mujer en el momento de acudir a la Administración de Justicia», pág. I45.

${ }^{54}$ Según un comunicado de prensa, publicado el 5 de septiembre de 2006 y firmado, entre otras, por la Federación de Mujeres Progresistas y la de Mujeres Separadas y Divorciadas, la Unión de Asociaciones Familiares, la Asociación Vivir sin Violencia, Asociación de Mujeres Juristas (Themis).

${ }^{55}$ Informe anual, 2007, p. I88.

${ }^{56}$ Como reconoce el propio Informe, 2007, p. I89.

${ }^{57}$ Añón, MJ./Mestre,R., 2005, pág. 42. Una idea similar en Acale,M., 2006, pág. II7. Es significativo que, en orden a evitar esa indeseable victimización femenina, un sector del feminismo más crítico propugne seriamente visibilizar las violencias perpetradas por las mujeres frente al hombre y frente al grupo doméstico. ¿ No es esto violencia de género?, se pregunta Osborne, 2007, criticando que se invisibilice un dato que, sin embargo, estaba presente en las Macroencuestas realizadas por el Instituto de la Mujer realizadas en 2000 En la misma línea Izquierdo, MJ. propone analizar esa otra cara de la violencia de género, como medio para poner en cuestión la división sexual del trabajo y sacar de la esfera privada las tareas de cuidado que, histórica y culturalmente, pesan sobre la mujer. Estructura y acción en la violencia de género (citado con la autorización de la autora).
} 